\title{
Increased sensitivity of gastrin release to adrenaline in duodenal ulcer ${ }^{1}$
}

\author{
O. BRANDSBORG, ${ }^{2}$ N. J. CHRISTENSEN, N. A. LøVGREEN, M. BRANDSBORG, \\ AND J. F. REHFELD \\ From the Surgical Department of Gastroenterology, 2nd Clinic of Internal Medicine, Kommunehospitalet, \\ Medical Department I and II, Amtssygehuset and Institute of Medical Biochemistry, University, Aarhus, \\ Denmark
}

SUMMARY Serum gastrin concentrations were measured in patients with duodenal ulcer and controls before, during, and after one-hour intravenous infusion of various doses of adrenaline $(0.12 \mu \mathrm{g}$ to $6 \mu \mathrm{g} / \mathrm{min})$. Gastrin concentrations in the basal state were significantly increased in duodenal ulcer patients compared to controls. The maximal rise in serum gastrin concentrations was obtained at a dose of $4 \mu \mathrm{g} / \mathrm{min}$ adrenaline in both groups of subjects, and the increase was significantly higher in duodenal ulcer patients than in controls. Adrenaline increased predominantly the gastrin III component (gastrin-17 like) in both duodenal ulcer patients and controls. The threshold level of adrenaline-induced gastrin release was significantly lower in duodenal ulcer patients: intravenous infusion of adrenaline in a dose of $0.12 \mu \mathrm{g}$ and $0.25 \mu \mathrm{g} / \mathrm{min}$ increased serum gastrin concentrations 23 and $43 \%$, respectively, but had no effect in controls. Rises in plasma adrenaline concentrations were similar in both groups of subjects in response to the various doses of adrenaline employed. Only the smallest dose of adrenaline $(0.12 \mu \mathrm{g} / \mathrm{min})$ resulted in clearly physiological variations in plasma adrenaline concentrations. The results indicate that endogenous adrenaline may stimulate the secretion of gastrin during physiological conditions in patients with duodenal ulcer.

Adrenaline stimulates the secretion of gastrin in man and is at least partially responsible for the rise in serum gastrin concentrations during hypoglycaemia (Hayes et al., 1972; Stadil and Rehfeld, 1973; Kronborg et al., 1974; Brandsborg et al., 1975; Kaess et al., 1975).

Previous studies have demonstrated a relationship between plasma adrenaline and serum gastrin concentrations during hypoglycaemia as well as between intravenous infusion of adrenaline and rise in serum gastrin (Stadil and Rehfeld, 1973; Brandsborg et al., 1975; Christensen and Stadil, 1976). However, the threshold level for plasma adrenalinestimulated gastrin release has not been elucidated and may be reduced in patients with duodenal ulcer. We have previously observed that a fixed dose of isoprenaline resulted in much greater serum gastrin concentrations in patients with duodenal ulcer than

${ }^{1}$ This study was supported by grants from the Danish Medical Research Council (Nos. 512-7093 and 512-7278).

'Address for reprint requests: $O$. Brandsborg, Surgical Department of Gastroenterology, Kommunehospitalet, Aarhus, Denmark.

Received for publication 10 October 1977 in control subjects (Brandsborg et al., 1976).

The present study concerns the interrelationship between intravenous infusion of adrenaline, plasma adrenaline concentration, and serum gastrin in patients with duodenal ulcer and controls.

\section{Methods}

\section{SUBJECTS AND PROCEDURE}

Twenty-one normal male subjects (mean age 34 years, range 25-47 years) and 19 male patients (mean age 38 years, range 26-51 years) with radiologically verified non-obstructing duodenal ulcer participated in 35 and 40 infusion experiments, respectively. An informed consent to the procedure was obtained from all subjects examined.

The study was performed in the morning with subjects resting in the supine position after an overnight fast. Adrenaline was infused intravenously for one hour in both groups of subjects in the following doses: $0.25 \mu \mathrm{g} / \mathrm{min}, 1 \mu \mathrm{g} / \mathrm{min}, 2 \mu \mathrm{g} / \mathrm{min}$, $4 \mu \mathrm{g} / \mathrm{min}$, and $6 \mu \mathrm{g} / \mathrm{min}$. A dose of $0.12 \mu \mathrm{g} / \mathrm{min}$ for one hour was given to the duodenal ulcer patients only. Each dose of adrenaline was given to six to 
eight duodenal ulcer patients and six to eight controls. For practical reasons it was not possible to give each dose of adrenaline to each individual subject. Twenty-two subjects participated in one experiment, while eight, six, two, and each of two subjects participated in two, three, four, five, and six different infusion experiments, respectively. The subjects who participated in more than one experiment were given each dose of adrenaline on different days and in a randomised order.

Adrenaline was infused into an antecubital vein. Venous blood was collected through a catheter in the opposite arm. Blood for measurement of serum gastrin concentrations was collected in the basal state (two samples) and at 10, 20,30, 45, and 60 minutes during the infusion and 15 and 30 minutes after the infusion was stopped.

Blood for measurement of plasma noradrenaline and adrenaline was collected before and at the end of the infusion period from two duodenal ulcer patients and two controls at each dose of adrenaline employed.

\section{TECHNIQUES}

Serum gastrin concentrations were measured by radioimmunoassay using two different antisera. The gastrin antiserum (4562) (Rehfeld et al., 1972) reacted on a molar base equally well with components I, II (gastrin-34 like) and III (gastrin-17 like) (Rehfeld, 1976). Monoiodinated gastrin-17 was used as tracer (Stadil and Rehfeld, 1972). The serum gastrin component III (gastrin-17 like) was determined by an antiserum (Dockray and Taylor, 1976) (L6) specific for gastrin-17 (a generous gift from G. Dockray, Liverpool). Plasma noradrenaline and adrenaline were determined by double-isotope derivative assay (Engelman and Portnoy, 1970; Christensen, 1973).

Wilcoxon test for two samples and for pair differences was used for the statistical analysis (Geigy J. R., 1962). Regression analysis was performed according to the method of Bailey (Bailey, 1959).

\section{Results}

The basal serum gastrin concentrations were significantly greater in duodenal ulcer patients than in controls (median 50 (range 29 to 142) and median 24 (range 12 to 51 ) $\mathrm{pg} / \mathrm{ml}$, respectively, $2 \mathrm{P}<0.01$ ).

Figure 1 shows serum gastrin concentrations in individual patients and controls before, during and after intravenous infusion of adrenaline in a dose of $2 \mu \mathrm{g} / \mathrm{min}$ for one hour. Serum gastrin was increased at 10 minutes after start of the infusion and returned rapidly to basal concentrations after the infusion was stopped. Rise in serum gastrin was related to basal serum gastrin concentration in duodenal ulcer patients during adrenaline infusion $(0 \cdot 12,0 \cdot 25$ and $1 \mu \mathrm{g} / \mathrm{min}, 2 \mathrm{P}<0.05$ to 0.001 ).

Figure 2 shows mean rise in serum gastrin concentration in response to the different infusion doses of adrenaline employed. Results are expressed either in absolute values or expressed as percentage of basal values.

Intravenous infusion of adrenaline increased serum gastrin concentrations in duodenal ulcer patients at all levels of stimulation $(2 \mathrm{P}<0.05$ to $0 \cdot 01$ ). The greatest response was obtained at $4 \mu \mathrm{g} / \mathrm{ml}$. Adrenaline in a dose of $0.25 \mu \mathrm{g} / \mathrm{min}$ had no effect

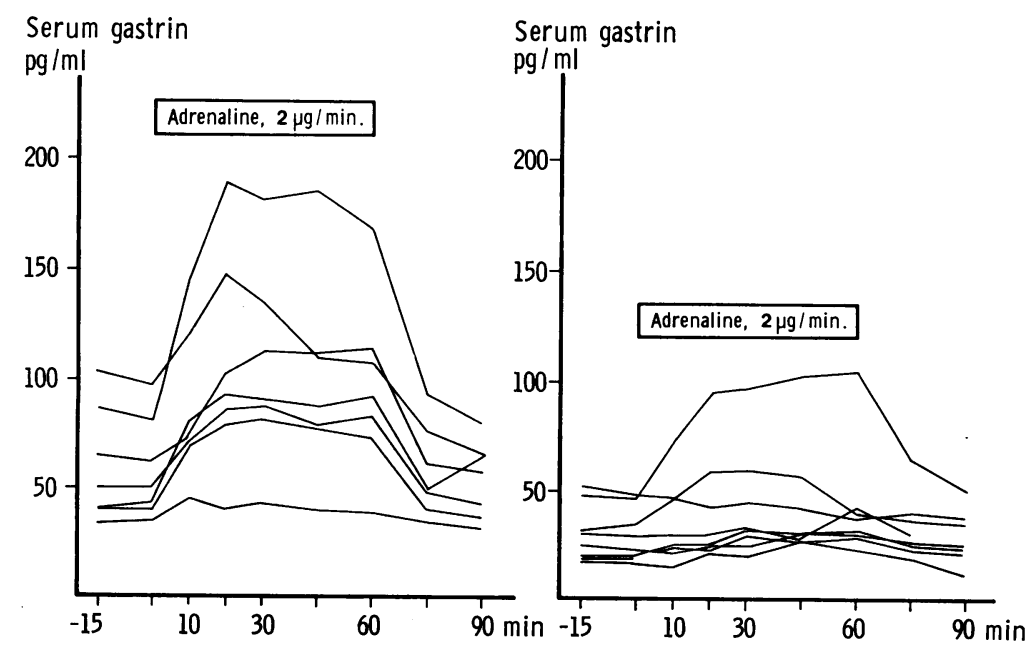

Fig. 1 Serum gastrin $(\mathrm{pg} / \mathrm{ml})$ in individual patients and controls before, during and after intravenous infusion of adrenaline in a dose of $2 \mu \mathrm{g} / \mathrm{min}$ for one hour. Left: duodenal ulcer patients. Right: controls. 


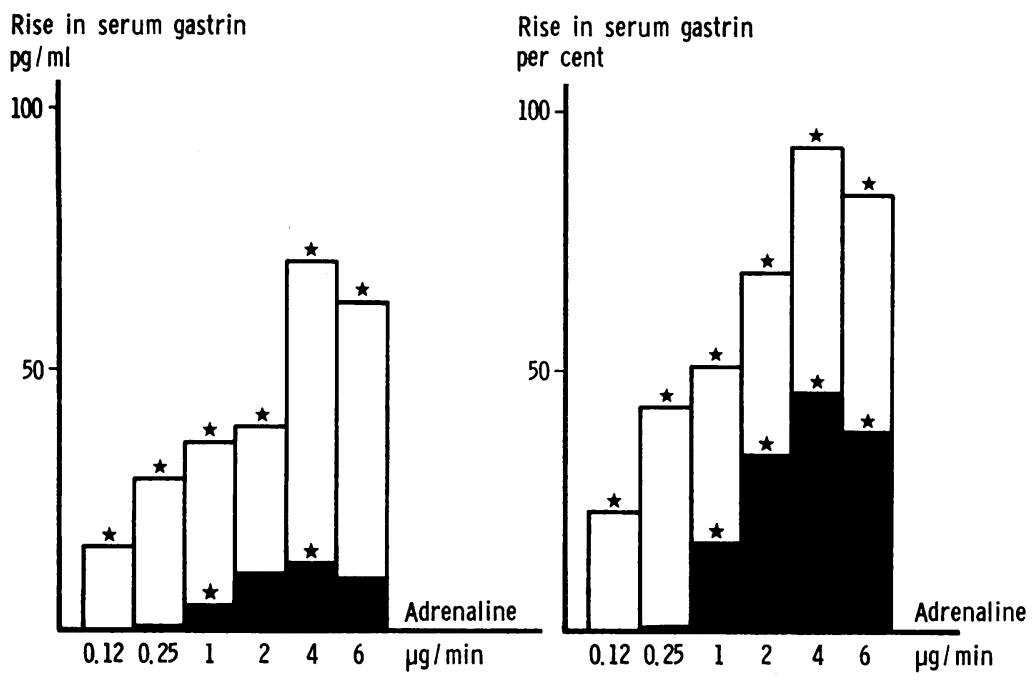

Fig. 2 Mean rise in serum gastrin $(\mathrm{pg} / \mathrm{ml}$ ) in patients (open columns) and controls (closed columns) in response to the different doses of adrenaline employed. Left: absolute values. Right: expressed as percentage of basal values. * Mean value significantly different from zero. on serum gastrin in normal subjects while subsequent higher doses increased serum gastrin significantly $(2 \mathrm{P}<0.05$ to 0.02$)$.

Rise in serum gastrin concentrations was significantly greater in duodenal ulcer patients than in controls at all doses of adrenaline employed $(2 \mathrm{P}<0.05$ to 0.01$)$. Expressed as a percentage of basal values rise in serum gastrin was significantly higher in patients than in controls at an infusion dose of 0.25 and $1 \mu \mathrm{g} / \mathrm{min}$ adrenaline. $(2 \mathrm{P}<0.02$ to 0.01 ) but not at 2,4 , and $6 \mu \mathrm{g} / \mathrm{min}$. There was some variation in the gastrin response among different subjects at the same intravenous dose of adrenaline. The shape of the dose-response curve in two subjects who participated in several different experiments approximated to a straight line over the range 0.25 to $4 \mu \mathrm{g} / \mathrm{min}$ (Fig. 3 ).

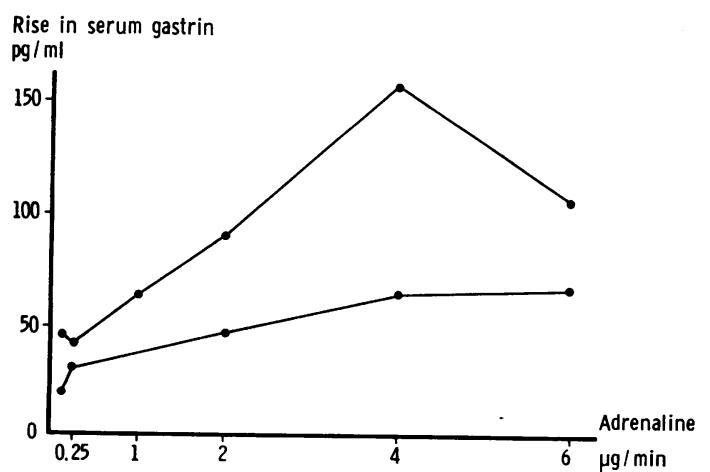

Fig. 3 The relationship between intravenous infusion dose of adrenaline (abscissa) and rise in serum gastrin ( $\mathrm{pg} / \mathrm{ml})$ above basal values in two patients who participated in several different experiments.
The Table shows the concentrations of component III and total gastrin in serum in two duodenal ulcer patients and three controls in response to adrenaline in a dose of 2 or $4 \mu \mathrm{g} / \mathrm{min}$. The gastrin component III increased in all subjects.

Mean basal plasma noradrenaline concentrations were significantly higher in duodenal ulcer patients than in controls $(0.26$ and $0.16 \mathrm{ng} / \mathrm{ml}$, respectively, $2 P<0.01$ ), while plasma adrenaline concentrations were similar $(0.03$ and $0.04 \mathrm{ng} / \mathrm{ml}$, respectively). At the end of the infusion plasma noradrenaline averaged $0.38 \mathrm{ng} / \mathrm{ml}$ in the patients and $0.18 \mathrm{ng} / \mathrm{ml}$ in the controls $(2 \mathrm{P}<0.02)$.

Figure 4 shows the rise in plasma adrenaline concentrations at the end of the infusion periods. Each symbol is the mean of two values obtained in two different subjects at each dose of adrenaline employed. The dose-response curves are very similar in patients and controls.

\section{Discussion}

The present study shows, in agreement with our previous findings (Brandsborg et al., 1976; Brandsborg et al., in press), that serum gastrin and plasma noradrenaline concentrations are increased and plasma adrenaline is the same in patients with duodenal ulcer compared to normal subjects. We have previously shown (Brandsborg et al., 1976) that intravenous infusion of isoprenaline, a betaadrenergic agonist, in a dose of $2 \mu \mathrm{g} / \mathrm{min}$ resulted in greater serum gastrin concentrations in patients with duodenal ulcer than in normal subjects. This finding has now been extended to adrenaline, which in all doses employed resulted in a greater rise in serum gastrin concentrations in patients with duodenal 
Table G-17 and total gastrin concentrations $(\mathrm{pg} / \mathrm{ml})$ in serum obtained in three normal subjects and two patients with duodenal ulcer before, during, and after a 60 minute period infusion of adrenaline

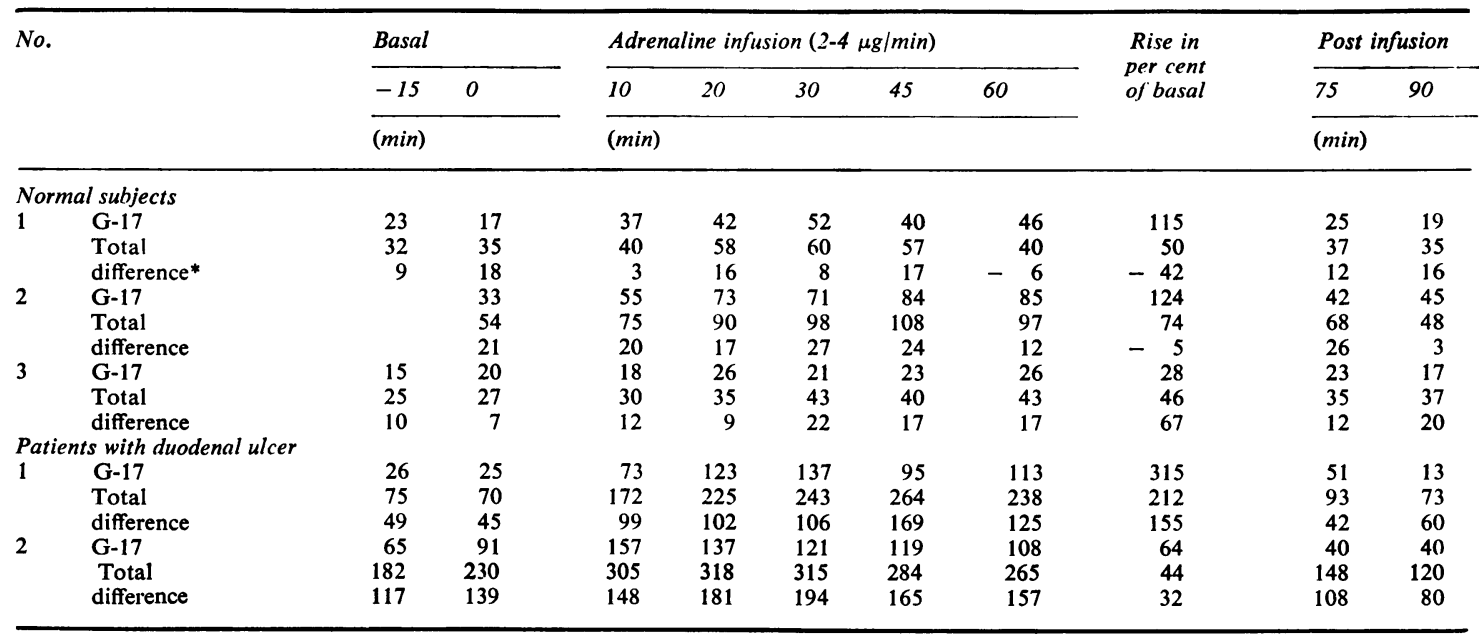

* Mainly gastrin component II.

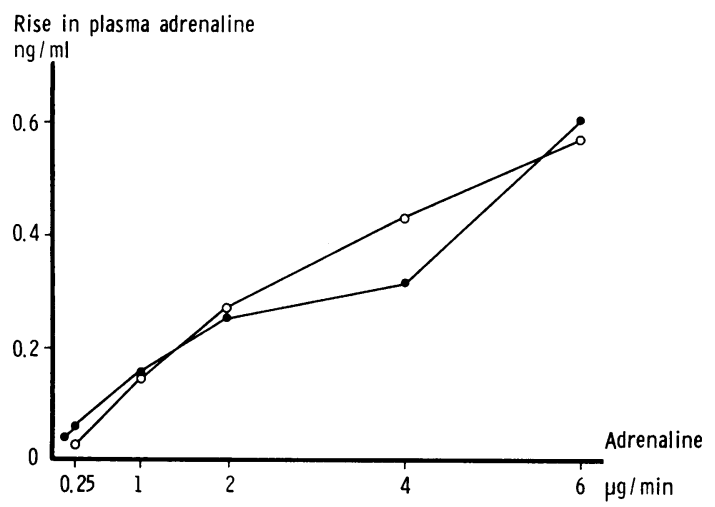

Fig. 4 The relationship between intravenous infusion dose of adrenaline (abscissa) and rise in plasma adrenaline ( $\mathrm{ng} / \mathrm{ml}$ ) above basal values (ordinate). Each symbol is the mean of two values obtained in two different subjects at each dose of adrenaline employed. (O) controls, (O) duodenal ulcer patients.

ulcer than in controls. The most important observation is, however, that the threshold level for adrenaline-stimulated gastrin release is considerably decreased in duodenal ulcer patients. The higher serum gastrin concentrations in the patients was not due to higher plasma adrenaline concentrations during intravenous adrenaline infusions, because similar concentrations were obtained in both groups of subjects in response to the various doses of adrenaline employed.

The gastrin component III in serum was determined only in a limited number of subjects. These data suggest that adrenaline increased predominantly the component III in both patients and controls.

In normal subjects intravenous infusion of adrenaline in a dose of $1 \mu \mathrm{g} / \mathrm{min}$ increased serum gastrin concentrations $17 \%$ over basal values and plasma adrenaline $0.15 \mathrm{ng} / \mathrm{ml}$, while the lower dose of $0.25 \mu \mathrm{g} / \mathrm{min}$ adrenaline had no effect on serum gastrin concentrations. This indicates that plasma adrenaline is unlikely to be an important regulator of gastrin secretion in normal subjects during physiological conditions except during prolonged exercise, which may increase plasma adrenaline 10-fold (Galbo et al., 1976). However, our data are entirely compatible with a number of previous observations indicating that the rise in plasma adrenaline concentrations during hypoglycaemia from $0.04 \mathrm{ng} / \mathrm{ml}$ to approximately $1.00 \mathrm{ng} / \mathrm{ml}$ is responsible for the concomitant rise in serum gastrin (Hayes et al., 1972; Stadil and Rehfeld, 1973; Kronborg et al., 1974; Brandsborg et al., 1975; Kaess et al., 1975).

The situation is different in patients with duodenal ulcer. The eight-fold lower dose of adrenaline $(0.12 \mu \mathrm{g} / \mathrm{min})$ raised serum gastrin concentrations $23 \%$ and plasma adrenaline $0.04 \mathrm{ng} / \mathrm{ml}$. A change as small as this in plasma adrenaline occurs in response to standing, smoking, and mild exercise, which may double plasma adrenaline concentration (Christensen and Brandsborg, 1973; Christensen and Brandsborg, 1976; Brandsborg et al., in press; Brandsborg et al., submitted). Studies in our laboratory have shown that smoking and exercise of moderate intensity and duration increase serum 
gastrin concentrations in duodenal ulcer patients, probably because of a rise in plasma adrenaline (Brandsborg et al., submitted). Adrenaline secretion may therefore influence the secretion of gastrin during physiological conditions in patients with duodenal ulcer.

The cause of the increased sensitivity of gastrin cells to adrenaline in patients with duodenal ulcer remains unexplained. It is unlikely to be due to a specific abnormality of the beta-adrenergic receptors. There is no generalised increased responsiveness to beta-adrenergic stimulation-for example, insulin secretion and pulse rate-in duodenal ulcer patients (Brandsborg et al., 1976). Furthermore, mealstimulated gastrin secretion is also considerably increased in duodenal ulcer patients and propranolol has no effect on meal-stimulated gastrin secretion in a dose which completely inhibits isoprenalinestimulated gastrin secretion (Brandsborg et al., 1976). G-cell hyperplasia may, if it exists in duodenal ulcer patients (Creutzfeldt et al., 1976), explain the higher maximal response of serum gastrin to adrenaline. However, such a mechanism is unlikely to be responsible for the decreased threshold level of gastrin release to adrenaline stimulation.

The increased adrenaline sensitivity is probably secondary to an abnormality of the gastrin producing cells, either in the secretory apparatus or due to defective inhibitory secretory processes.

\section{References}

Bailey, N. T. J. (1959). Statistical Methods in Biology. English Universities Press London.

Brandsborg, O., Brandsborg, M., and Christensen, N. J. (1975). Plasma adrenaline and serum gastrin: studies in insulin-induced hypoglycemia and after adrenaline infusions. Gastroenterology, 68, 455-460.

Brandsborg, O., Brandsborg, M., and Christensen, N. J. (1976). The role of the beta-adrenergic receptor in the secretion of gastrin: studies in normal subjects and in patients with duodenal ulcers. European Journal of Clinical Investigation, 6, 395-401.

Brandsborg, O., Brandsborg, M., Løvgreen, N. A., and Christensen, N. J. (1978). Increased plasma noradrenaline and serum gastrin in patients with duodenal ulcer. European Journal of Clinical Investigation, in press.

Brandsborg, O., Christensen, N. J., Galbo, H., Brandsborg, M., and Løvgreen, N. A. The effect of exercise, smoking and propranolol on serum gastrin in patients with duodenal ulcer. Submitted for publication.

Christensen, N. J. (1973). Plasma noradrenaline and adrenaline in patients with thyrotoxicosis and myxoedema. Clinical Science, 45, 163-171.

Christensen, N. J., and Brandsborg, O. (1973). The relationship between plasma catecholamine concentration and pulse rate during exercise and standing. European Journal of Clinical Investigation, 3, 299-306.

Christensen, N. J., and Brandsborg, O. (1976). The effect of standing and exercise on plasma catecholamines, serum insulin, and serum gastrin. Scandinavian Journal of Clinical and Laboratory Investigation, 36, 591-595.

Christensen, K. C., and Stadil, F. (1976). Effect of epinephrine and norepinephrine on gastrin release and gastric secretion of acid in man. Scandinavian Journal of Gastroenterology, vol. 11, Suppl. 37, 87-92.

Creutzfeldt, W., Arnold, R., Creutzfeldt, C., and Track, N. S. (1976). Mucosal gastrin concentration, molecular forms of gastrin, number and ultrastructure of G-cells in patients with duodenal ulcer. Gut, 17, 745-754.

Dockray, G. J., and Taylor, I. L. (1976). Heptadecapeptide gastrin: measurement in blood by specific radioimmunoassay. Gastroenterology, 71, 971-977.

Engelman, K., and Portnoy, B. (1970). A sensitive doubleisotope derivative assay for norepinephrine and epinephrine. Circulation Research, 26, 53-57.

Galbo, H., Holst, J. J., Christensen, N. J., and Ililsted, J. (1976). Glucagon and plasma catecholamines during betareceptor blockade in exercising man. Journal of Applied Physiology, 40, 855-863.

Geigy, J. R. (1962). Scientific Tables. Sixth Edition. Edited by K. Diem. Geigy (Documenta Geigy): Ardsley, N. Y.

Hayes, J. R., Ardill, J., Kennedy, T. L., Shanks, R. G., and Buchanan, K. D. (1972). Stimulation of gastrin release by catecholamines. Lancet, 1, 819-821.

Kaess, H., Kuntzen, O., Teckentrupp, U., and Dörner, M. (1975). The influence of propranolol on serum gastrin concentration and hydrochloric acid secretion in response to hypoglycemia in normal subjects. Digestion, 13, 193-200.

Kronborg, O., Pedersen, T., Stadil, F., and Rehfeld, J. F. (1974). The effect of beta-adrenergic blockade upon gastric acid secretion and gastrin secretion during hypoglycemia before and after vagotomy. Scandinavian Journal of Gastroenterology, 9, 173-176.

Rehfeld, J. F., Stadil, F., and Rubin, B. (1972). Production and evaluation of antibodies for the radioimmunoassay of gastrin. Scandinavian Journal of Clinical and Laboratory Investigation, 30, 221-232.

Rehfeld, J. F. (1976). Disturbed islet-cell function related to endogenous gastrin release. Journal of Clinical Investigation, 58, 41-49.

Stadil, F., and Rehfeld, J. F. (1972). Preparation of ${ }^{125}$ Ilabelled synthetic human gastrin I for radioimmunoanalysis. Scandinavian Journal of Clinical and Laboratory Investigation, 30, 361-368.

Stadil, F., and Rehfeld, J. F. (1973). Release of gastrin by epinephrine in man. Gastroenterology, 65, 210-215. 